\title{
Paradigmas do desenvolvimento cognitivo: uma breve retrospectiva
}

\author{
Suely de Melo Santana \\ Universidade Católica de Pernambuco \\ Antonio Roazzi \\ Maria das Graças B. B. Dias \\ Universidade Federal de Pernambuco
}

\begin{abstract}
Resumo
A cognição humana tem sido foco de diversas investigações no campo da psicologia do desenvolvimento, buscando-se construir um referencial teórico-empírico para orientar estudos e intervenções nesta direção. O debate tem se situado em torno de grandes paradigmas - piagetiano, neopiagetiano, processamento informacional, contextual e biológico-maturacional/neurociência cognitiva, sendo considerados, por vezes, enquanto referencial absoluto de verdade, e percebidos como excludentes entre si. O objetivo deste trabalho consiste em realizar uma breve retrospectiva dessas vertentes teóricas, buscando identificar pontos de interlocução entre elas, na tentativa de apreendê-las enquanto um corpo de conhecimentos que se complementam e integram vários olhares sobre a mente humana.
\end{abstract}

Palavras-chave: desenvolvimento cognitivo; cognição humana; paradigmas

\begin{abstract}
Paradigms of cognitive development: a brief retrospect. The human cognition has been focused by diverse inquiries in the field of the development psychology, searching to construct a theoretician-empiricist referential to guide studies and interventions in this direction. The debate has been situated around great paradigms Piagetian, Neopiagetian, informational and contextual processing and cognitive biological-maturational/ neuroscience, being considered, sometimes, as an absolute referential of truth, and perceived as excludents among them. The objective of this work consists in carrying through a brief retrospect of these theoretical sources, searching to identify interlocution points between them, in the attempt to apprehend them while a body of knowledge that can complement and integrate some views about human mind.
\end{abstract}

Keywords: cognitive development; human cognition; paradigms

A integração de saberes advindos da biologia, da neurologia, da física e da matemática, ao longo da história da psicologia, tem em muito contribuído para desvendar a complexidade, riqueza e sutileza do funcionamento humano. O percurso histórico das concepções sobre a mente, contribuiu para o incremento das investigações no campo da psicologia do desenvolvimento, principalmente a partir do século XX, quando os estudos sobre a cognição e seus processos passaram a receber um enfoque diferenciado, resultando num avanço dos conhecimentos na área da cognição humana.

\section{Desenvolvimento cognitivo}

As teorias que investigam a natureza e o desenvolvimento cognitivo humano podem ser especificadas, segundo Flavell, Miller e Miller (1999), em quatro principais abordagens, a saber: o paradigma piagetiano; a perspectiva neopiagetiana; a abordagem do processamento de informa- ções e o paradigma contextual. Ademais, outras duas abordagens começam a ser referenciadas nesta área: a biológicomaturacional e a abordagem do conhecimento baseado em teorias.

\section{O paradigma piagetiano}

Este paradigma destaca-se, sobretudo, pela influência marcante que exerceu sobre a psicologia do desenvolvimento, sendo um dos mais representativos e mais abrangentes nesta área. Até o final dos anos 70, Piaget dedicou-se ao aprofundamento das teses epistemológicas e a ampliação da psicologia genética no tocante aos aspectos dinâmicos do pensamento e, posteriormente, passou a enfatizar o estudo empírico do funcionamento cognitivo e seu papel fundamental enquanto propulsor do desenvolvimento, fazendo com que o construtivismo fosse o melhor definidor de sua obra nesse período (Coll \& Gillièron, 1987). Ele direcionou suas investigações para o desenvolvimento qualitativo das estru- 
turas intelectuais através de uma análise ontogenética que favoreceu a compreensão do comportamento humano adulto a partir de uma perspectiva evolutiva (Flavell, 1988).

A inteligência, na concepção piagetiana, organiza-se através de estruturas que atuam como mediadoras entre as funções invariantes e os diversos conteúdos comportamentais. Estes últimos variam de acordo com a idade e são caracterizados pelos dados comportamentais brutos, enquanto que as funções definem a própria essência, as características amplas da atividade inteligente, e que não variam em função da idade. Os invariantes funcionais básicos são, por conseguinte, a organização e a adaptação que se compõe dos processos inter-relacionados de assimilação e acomodação. Sendo assim, "a atividade inteligente é sempre um processo ativo e organizado de assimilação do novo ao velho e de acomodação do velho ao novo" (Flavell, 1988, p. 17). Em outras palavras, pode-se dizer que “assim como os objetos precisam ajustar-se à estrutura peculiar do organismo em qualquer processo adaptativo (assimilação), o organismo também precisa ajustar-se às exigências idiossincráticas do objeto (acomodação)” (p. 45).

A relação existente entre formação de pensamento e aquisição da linguagem, na visão piagetiana, configura-se de caráter apenas correlacional, sendo o pensamento constituído por um processo bem mais amplo que remete ao desenvolvimento da função simbólica. Desse modo, na concepção piagetiana, defende-se que a maneira como a criança faz uso da linguagem, exprime o tipo de lógica que caracteriza seu pensamento. Afora isso, advoga-se também que a linguagem da criança preenche outras funções além da comunicação, observando, por exemplo, que durante seu desenvolvimento, a linguagem pode ser duplamente categorizada, ou seja, ela pode ser apreendida enquanto uma linguagem egocêntrica ou enquanto uma linguagem socializada (Flavell, 1988). Nesta concepção, existe uma lógica das ações que precede a aquisição da linguagem e que se encontra numa fase pré-verbal, anterior ao desenvolvimento da função semiótica, contrariando a tendência do empirismo lógico de vincular a gênese de todas as operações intelectuais à linguagem, através da tentativa de explicar o caráter operativo da lógica enquanto circunscrito aos aspectos sintático, semântico e pragmático da mesma. Assim, Piaget (1973) postula a diferenciação entre linguagem e lógica, alegando que, apesar da linguagem ser um importante instrumento, uma ferramenta expressiva do conhecimento, ela não é suficiente para a formação das estruturas operatórias, principalmente das estruturas lógico-matemáticas. Em sua concepção, existe um sujeito prévio, epistêmico, capaz de organizar suas ações sensório-motoras, fazer inferências práticas a partir de seu conhecimento de mundo.

Os esquemas, já no período sensório-motor (aproximadamente de 0 a 2 anos de idade), diferenciam-se das ações pelo fato de conservarem uma certa organização interna cada vez que aparecem, constituindo-se em uma unidade básica do funcionamento cognitivo e no ingrediente elementar de todas as formas de pensamento. Assim, inicialmente, o bebê desenvolveria esquemas reflexos, que se configuram em ações espontâneas e automáticas diante de certos estímulos, tais como esquema de sugar, esquema de preensão, etc. Paulatinamente, esses esquemas vão sendo submetidos a um processo de diferenciação que conduz à construção de esquemas de ação que, ao se coordenarem, favorecem a construção de novos esquemas. Por volta dos 2 anos de idade, esses esquemas de ação, devido ao surgimento da função simbólica, convertem-se em esquemas representativos, ou seja, em esquema de ação interiorizado (Coll \& Gillièron, 1987).

De acordo com Piaget (1973), os esquemas seriam uma espécie de conceitos práticos, decorrentes de algo generalizável a partir de uma dada ação. Estes esquemas esboçariam o início das estruturas de classes e de relações, que, ao generalizarem-se, permitiriam à criança realizar uma espécie de classificação. Estabelecidas essas classes, observa-se, por um lado, uma compreensão - das qualidades que fundamentam a generalização - e, por outro, uma extensão que consiste no conjunto de situações a que se aplicam. Contudo, essa extensão encontra-se limitada ao comportamento observado, uma vez que a criança carece de uma função simbólica que lhe permita representá-la. Vários tipos de relações estão envolvidos nos esquemas, que, tomando-se o caso da atividade de empilhar cubos de diversos tamanhos, resultariam numa forma de seriações sensório-motoras. Desse modo, a coordenação de esquemas variados, conduziria a inferências práticas que comportariam, posteriormente, as noções de conservação e reversibilidade operatória.

Em seu desenvolvimento, a criança constrói vários e diferenciados esquemas que tendem a formar combinações, dando origem às estruturas cognitivas, que traduzem uma forma particular de equilíbrio na interação do indivíduo com o ambiente. Na perspectiva piagetiana, a linguagem apenas favorece a interiorização das ações quando as estruturas já estão elaboradas, possibilitando a assimilação de informações verbais que estejam consoantes com o nível de elaboração das mesmas. As crianças em idade pré-escolar, nesta concepção, ainda não conseguem fazer a distinção entre estados mentais e físicos, assim como também apresentam dificuldades outras que remetem à questão do egocentrismo, uma vez que a criança pequena percebe-se como centro do universo, "pois ela não tem consciência de que as outras vêem as coisas de modo diferente, isto é, que seu ponto de vista é apenas um entre muitos outros” (Flavell, 1988, p. 278).

A linguagem, em seu desenvolvimento, nivela-se ao jogo simbólico, à imitação diferida e à imagem mental enquanto imitação interiorizada. Consoante com os pressupostos de Wallon, Piaget (1973) concebe que a imitação garante a transição das condutas sensório-motoras para as condutas simbólicas ou representativas, uma vez que sua diferenciação e interiorização permitem a distinção entre significantes e significados. Essa acepção vincula-se diretamente ao desenvolvimento da função simbólica, a qual favorece o aparecimento da representação simbólica (símbolo) e da representação conceitual (signo). Piaget (1978) situa os primórdios desse 
desenvolvimento no índice sensório-motor - que consiste apenas em uma parcela ou aspecto do objeto que permite antecipá-lo sem representação mental, simplesmente por meio de uma ativação do esquema interessado. A presença desse índice, por exemplo, encontra-se no fato de que a "criança de oito a nove meses já saberá reencontrar um brinquedo debaixo de uma coberta qualquer, quando a forma estufada desta serve de indício à presença do objetivo" (p. 129). De forma diferente, no entanto, Piaget salienta a distinção em relação ao símbolo, que já consiste numa representação, uma vez que repousa numa semelhança entre o objeto presente (significante) e o objeto ausente (significado), visto que uma situação passada é mentalmente evocada. Observa-se, no entanto, que existe a necessidade, nessa representação simbólica, de uma correspondência com o significado, fazendo com que o símbolo seja caracteristicamente motivado, o que já o distingue substancialmente do signo, cujo caráter primordial reside na arbitrariedade e na pressuposição de uma relação social que o legitime.

Essa conquista assegura o estabelecimento da função simbólica que subsidia o pensamento representativo, uma vez que permite o envolvimento simultâneo de eventos isolados, de forma a promover uma síntese interna e única. Em outras palavras, possibilita à criança evocar o passado, representar o presente e antecipar o futuro, por meio de um ato organizado e temporalmente curto (Flavell, 1988). Com a função simbólica, há uma diferenciação dos esquemas de ação em esquemas representativos. "A possibilidade de executar uma série de ações organizadas se enriquece com a possibilidade de se imaginar e de executar tais ações através de representações” (Coll \& Gillièron, 1987, p. 39). Na concepção piagetiana "a função simbólica é uma aquisição muito geral e básica que torna possível a aquisição de símbolos privados e de signos sociais” (Flavell, 1988, p. 157). As operações consistem em sistemas relativamente complexos que estão aquém e além da linguagem, mas, no entanto, com relação às operações proposicionais que se desenvolvem entre 11 e 15 anos de idade, há uma maior dependência da linguagem, já que se encontram mais relacionadas à comunicação verbal e, deste modo, seria difícil concebêlas sem o uso da linguagem (Piaget, 1973). Durante esse período, observa-se que as operações se desvinculam paulatinamente do plano concreto, favorecendo o surgimento do raciocínio hipotético-dedutivo, cuja utilização permite ao indivíduo "agrupar representações de representações em estruturas equilibradas” (Coll \& Gillièron, 1987, p. 41). Em outros termos, essa aquisição viabiliza ao adolescente pensar sobre o próprio pensar, evidenciando assim, a conquista de uma habilidade metacognitiva.

Foi justamente na tentativa de ratificar experimentalmente as postulações piagetianas que os pesquisadores começaram a identificar algumas inconsistências que tentaram suprir através de conhecimentos advindos de outras perspectivas teóricas. Assim, surge um novo referencial teórico, representado pela perspectiva neopiagetiana, que abordaremos a seguir.

\section{A perspectiva neopiagetiana}

Esta abordagem, de acordo com Flavell et al. (1999), resgata como paradigma básico a concepção estruturalista piagetiana, estabelecendo, no entanto, uma recorrência a outros paradigmas para preencher as lacunas evidenciadas na teoria, que, em linhas gerais, são expressas através da variabilidade do comportamento em função do contexto social, do tipo de tarefa, dos materiais e das instruções fornecidas às crianças. Sendo assim, a linguagem, na concepção dos teóricos pós-piagetianos (e.g., Astington, 2000; Flavell et al., 1999; Karmilloff-Smith, 1986; Olson, 1988), assume um papel bem mais preponderante na formação do pensamento do que o admitido na perspectiva piagetiana. Atribui-se a variabilidade a uma inconsistência observada na prática, quando crianças que deveriam apresentar as características de um determinado estágio não o fazem (por exemplo, deveriam conservar, mas não conservam; estão no período operatório-formal, mas demonstram um pensamento tipicamente operatório-concreto). De um modo mais específico, as divergências postas entre o pensamento piagetiano e os pós-piagetianos, residem em torno de quatro pontos básicos: noção de estrutura, mudanças qualitativas, passagens abruptas e coincidências (Flavell et al., 1999).

Quanto à noção piagetiana de estrutura enquanto um conjunto unificado de conhecimento ou habilidades cognitivas, os teóricos neopiagetianos tendem a considerála, sendo contrários, no entanto, à concepção de que estas estruturas operatórias têm um tipo definido e específico de organização, que obedece a modelos lógico-matemáticos que definem como a cognição estrutura-se nos estágios operatórios, concreto e formal. Esta contraposição respalda-se no fato desses modelos serem, por vezes, inconsistentes enquanto descrições teóricas dos processos mentais fundamentais. No tocante às mudanças de um estágio a outro, não se demonstram tão qualitativas nem tão abruptas quanto a concepção piagetiana fazia acreditar, sendo as mudanças mais graduais, importantes e extensas no tempo, assim como menos coincidentes do que seria de se esperar para uma caracterização de estágio. Alega-se, conforme citam Flavell et al. (1999), que a estabilidade que deveria suportar um estágio, na verdade, traduz-se num processo de mudança e transição contínuos, fazendo com que essa perda de previsibilidade reduza o valor científico do conceito de estágios, já que seria de se esperar que as competências advindas de um mesmo locus cognitivo emergissem mais ou menos ao mesmo tempo no desenvolvimento.

Isto posto, a perspectiva neopiagetiana busca suprir as incompletudes evidenciadas na teoria piagetiana através de outras abordagens, especialmente pelos processos de mudança providos pelo processamento de informação, uma vez que os conceitos são expressos mediante os processos de memória, atenção e estratégias em determinado ambiente, e a limitação da memória de curto prazo dificulta a expressividade dos mesmos. Flavell et al. (1999) comentam que a teoria de Case $(1985,1992)$ acerca da mudança cognitiva é considerada bem representativa dessa abordagem, enfatizando que: 
o desenvolvimento cognitivo é uma seqüência de procedimentos cada vez mais poderosos para a solução de problemas, juntamente com um conjunto cada vez mais eficiente de estruturas conceituais de conhecimento. Em uma tentativa de alcançar seus objetivos e subobjetivos, as crianças constróem novas estratégias ou empregam estratégias preexistentes adequadas. (Flavell et al., 1999, p. 18)

Esta constatação encontra ressonância nas considerações tecidas por Karmilloff-Smith (1986), no tocante ao processo de mudança pelo qual passam as representações internas das crianças. Na concepção desta autora, a consciência metalingüística exerce um papel essencial no desenvolvimento em geral, e o processo representacional sofre mudanças através de níveis de explicitação progressivos. Em linhas gerais, a transformação do conhecimento ocorreria, contrariamente à concepção piagetiana de desequilíbrio adaptativo, através da estabilidade, do equilíbrio. Assim, teria início a partir de um nível implícito - em que não se tem acesso consciente e não se encontra definido representacionalmente -, passando para um nível de explicitação primária - que envolve uma redescrição do código anterior -, que pode ser operado internamente, sem, contudo, ser diretamente acessível à consciência. Transpondo a dicotomia usual do implícito/explícito, ela defende a existência de um nível de explicitação secundária - no qual há uma segunda redescrição deste código representacional -, agora com acesso consciente, que evolui para um nível de explicitação terciária - no qual a múltipla representação do mesmo conhecimento em diferentes códigos torna-se explicitamente ligada por um código comum, abstrato, propiciando ao sistema cognitivo humano uma grande flexibilidade. Sendo assim, diferentemente da perspectiva piagetiana, os neopiagetianos "abordam a especificidade do domínio das habilidades cognitivas e dos aumentos evolutivos da capacidade mental” (Flavell et al., 1999, p. 24).

Considerando-se que as reflexões demandadas pelos estudos neopiagetianos foram marcadas pelas novas conceitualizações advindas da perspectiva do processamento de informações, apresenta-se, a seguir, esta outra abordagem.

\section{A abordagem do processamento de informação}

Esta abordagem surgiu com o advento tecnológico após a Segunda Guerra Mundial e como uma contraposição ao paradigma behaviorista. As descobertas neste âmbito promoveram uma revolução em diversas áreas de conhecimento, sendo particularmente influentes no campo da psicologia do desenvolvimento. Trouxeram um novo referencial para o estudo dos processos mentais, elucidando uma análise minuciosa e detalhada do desenvolvimento cognitivo. De acordo com Carvalho (1998), o físico e matemático A. Newell e o economista H. A. Simon, representantes desse paradigma computacional, defendiam que qualquer máquina capaz de processar símbolos poderia simular também os processos mentais. Nesta abordagem, a inteligência era considerada enquanto um processo de busca, por meio de estratégias heurísticas cada vez mais eficientes, para resolução de problemas.
Este novo paradigma, caracteristicamente simbolista e conexionista, concebe a mente enquanto um sistema complexo de caráter lógico e não físico, buscando legitimar-se por meio de uma analogia estabelecida entre a mente humana e o computador (Carvalho, 1998). Utilizando-se desta metáfora computacional para simular os processos mentais, esta abordagem considera que a mente humana apreende uma informação, faz sua conversão para uma representação mental, atribuindo-lhe um significado através da comparação com outras informações anteriormente processadas e, por fim, a conserva armazenada na memória (Flavell et al., 1999).

As informações processadas variam quanto à natureza, ao tamanho e aos níveis de complexidade. Existem informações do tipo declarativas, que remetem ao sentido das palavras e fatos, e informações procedimentais, que esclarecem a forma de operacionalização para a resolução do problema. As informações podem se organizar em unidades pequenas e elementares ou, ainda, como um todo organizado em um nível mais abstrato, composto por várias unidades elementares, tais como scripts de eventos (festa de aniversário, de casamento, etc.) e planificação de estratégia para a resolução de problema (Flavell et al., 1999). A mudança cognitiva, nesta perspectiva, seria impulsionada pela automatização dos processos mentais, definida por Siegler (1991) como uma progressiva e eficiente execução de procedimentos que promove a liberação de recursos mentais para outras finalidades. Esta eficiência seria alcançada em decorrência da prática e aprimoramento das estratégias. Outros elementos impulsionadores do desenvolvimento seriam o aumento na velocidade e a ampliação da capacidade de processamento. Modelar o processamento cognitivo em tempo real, de maneira tão precisa, explícita e detalhada, que seja viável acionar o modelo como um programa de computador, além de poder realizar previsões específicas sobre o comportamento de uma criança e de um computador, por exemplo, submetidos a uma determinada tarefa em condições específicas, consiste na meta mais idealizada e desejada desta abordagem (Flavell et al., 1999).

Contudo, existem limitações, até o momento, que inviabilizam esse objetivo e que são provenientes do quantitativo de informações que o sistema consegue simultaneamente processar, assim como das operações cognitivas (tais como codificar, comparar e recuperar informações da memória) que, em geral, requerem tempo e são realizadas de forma serial. Estas limitações citadas fazem com que a realização de apenas uma tarefa possa acarretar numa sobrecarga do sistema, por requerer uma quantidade de procedimentos que excedam a sua capacidade (Flavell et al., 1999). Afora estas, uma outra limitação, como já mencionada inicialmente, remete à consideração de que a perspectiva de trazer a mente de volta às ciências humanas, advogada inicialmente pela revolução cognitiva, foi substituída por uma ênfase acentuada nos processos de informação, negligenciando-se assim, a descoberta e descrição formal dos processos de produção de significados que emergem da interação entre os seres humanos e o mundo (Bruner, 1997). Ademais, e talvez, a mais complexa de 
todas as limitações, seja a questão singular da consciência ou, em outras palavras, o fato da mente humana, não apenas realizar tarefas, mas primordialmente ter a capacidade de vivenciá-las, de experimentar a consciência de seus processos. Talvez, como salienta Carvalho (1998), a consciência seja um princípio fundamental irredutível, da mesma maneira que a carga elétrica, o espaço e o tempo.

As considerações relativas à questão da construção de significados e da consciência, negligenciadas pela abordagem do processamento de informações são, de uma maneira bastante diferenciada, valorizadas enquanto foco essencial de interesse dentro do paradigma contextual, que será abordado a seguir.

\section{O paradigma contextual}

Este paradigma representa uma nova e importante fronteira na ciência psicológica, devido ao forte papel atribuído às interações no ambiente social enquanto propulsoras do desenvolvimento cognitivo. Aqui, toda psiquê humana constitui-se a partir do coletivo (percorrendo um caminho que vai do exógeno para o endógeno), sendo substancialmente distinta das concepções anteriores em que se advoga uma constituição intrinsecamente individual e interna, delegando-se ao contexto social, no máximo, a função de facilitar ou dificultar o desenvolvimento. O marco referencial dessa perspectiva sócio-interacionista vem principalmente dos trabalhos de Lev Semenovich Vygotsky, revolucionário marxista que adotou como referencial o materialismo dialético, desenvolvendo suas pesquisas ao longo de 10 anos em parceria com Alexander Romanovich Luria, Alexei Nikolaevich Leontiev e Leonid Solomonovich Sakharov. Devido a sua morte prematura, muitas de suas idéias não chegaram a ser concluídas (Vygotsky, 1993).

Na concepção vygotskyana, o estudo da consciência configura-se de primordial importância para a ciência da psicologia. Sua veemente oposição às duas correntes de pensamento dominantes na psicologia da época - a mecanicista e a idealista -, apoiava-se, por um lado, na desconsideração da consciência enquanto objeto de estudo da psicologia - evidenciada pelo behaviorismo - e, por outro, na abordagem à consciência sob os caminhos da introspecção, considerando-a enquanto fenômeno mental puramente subjetivo e exclusivamente interno. Assim, contrapondo-se à análise atomística e funcional da consciência, na qual os processos psíquicos eram investigados de maneira isolada, ele adotava uma perspectiva monista-holística (sistêmica), de que o desenvolvimento psíquico deveria ser estudado por meio dos sistemas psicológicos que integram a estrutura interfuncional da consciência (Leóntiev, 1999).

A gênese da consciência é atribuída, na concepção vygotskyana, à internalização dos processos interativos estabelecidos no ambiente social. Esta internalização, por sua vez, tem um caráter bastante dinâmico, não sendo caracterizada apenas como uma exata cópia interna das experiências (Wertsch, 1985). Ocorreria sim, por meio de uma reconstrução e resignificação dessa experiência, preservando, desta ma- neira, a unicidade e singularidade de cada indivíduo que partilha daquela interação social. Em outras palavras, o processo de internalização da experiência atuaria traduzindo-a de um nível interpsicológico para um intrapsicológico (Reig \& Gradolí, 1998). Então, a consciência, enquanto subjetividade, delineia-se a partir das relações interpessoais mediadas por ferramentas - instrumentos materiais - e signos - instrumentos psicológicos (Rego, 1995), e por mediação social através das atividades cooperativas entre os indivíduos (Alvarez \& Del Rio, 1996).

A defesa de um método dialético que contemple o estudo histórico dos processos de mudança, adotando uma análise do processo, das relações dinâmico-causais explicativas, possibilitando reconstruir todos os pontos do processo até a origem de uma certa estrutura, caracteriza o método vygotskyano enquanto experimental-desenvolvimentista. Estando além da análise fenotípica que identifica apenas as semelhanças externas dos fenômenos psíquicos, este método assegura a análise genotípica das funções psicológicas superiores, focalizando seus processos de construção e operacionalização, possibilitando abordar o desenvolvimento da criança em sua dialética complexidade (Vygotsky, 1998a). Afora a consideração histórica, este paradigma também postula a importância de se contemplar na análise as dimensões temporais (tempo filogenético, ontogenético, microgenético e tempo da história da humanidade), como caracteristicamente distintas e complementares (Lyra \& Seidl de Moura, 2000; Wertsch, 1985).

$\mathrm{Na}$ análise das mudanças cognitivas, o conceito de zona de desenvolvimento proximal (ZDP) assume um papel fundamental, que permite abordar o relacionamento existente entre o funcionamento intrapsicológico e interpsicológico. Esta apreensão favorece identificar a distância existente entre o nível de desenvolvimento potencial e o nível de desenvolvimento atual da criança (Wertsch, 1985), caracterizando o período intermediário que precede a evolução dos processos psicológicos humanos. Em linhas gerais, a ZDP consiste em um momento transitório no qual a criança, potencialmente capaz, consegue solucionar um determinado problema quando está em interação com outra criança mais evoluída ou com um adulto, mas ainda não consegue resolvê-lo por si mesma, sem a ajuda de terceiros (Flavell et al., 1999).

Além da dimensão social, a perspectiva vygotskyana considera as dimensões cognitiva e afetiva enquanto constituintes da consciência, vinculadas por meio de uma relação indissociável de construção e reconstrução dinâmica ao longo de todo o processo de desenvolvimento. Esta consideração integrada entre cognição e afeto apresenta-se como marcantemente distintiva com relação às demais teorias do desenvolvimento cognitivo, uma vez que, partindo-se de uma análise realizada por Vygotsky (1998b) sobre os estudos anatômicos, fisiológicos e psicológicos acerca da emoção, apesar de haver uma gradual e importante transferência da vida emocional de um locus extra-cerebral para a área cerebral e de uma esfera orgânica para uma psíquica, as emoções continuavam a ser consideradas de ordem inferior e isoladas de 
outros processos psíquicos considerados superiores. As concepções de que o fluxo de pensamentos não seria autônomo e desvinculado dos interesses e necessidades pessoais daquele indivíduo que pensa (Oliveira, 1992) e, ainda, que as emoções poderiam sofrer evolução e refinamento, transformando-se de maneira qualitativa de emoções primitivas infantis a emoções superiores dos adultos (van der Ver \& Valsiner, 1996) encontram respaldo na visão monista-holística, adotada por esta perspectiva.

Muitas das idéias germinadas no paradigma vygotskyano foram resgatadas por várias teorias contextualistas mais contemporâneas. Bruner (1997), por exemplo, investiga o locus da produção de significados na ação humana, assim como sua natureza e modelagem cultural, por meio do estudo de narrativas que constituem a psicologia popular. Ele defende o estatuto canônico dessa psicologia, alegando que ela sintetiza tanto o que as coisas são quanto o que deveriam ser. Dentro dessa concepção ele postula que "a psicologia popular trata de agentes humanos que fazem coisas com base em suas crenças e desejos, empenhando-se no atendimento a metas, encontrando obstáculos que eles dominam ou que os dominam, tudo isso se estendendo ao longo do tempo" (p. 46).

A metáfora da criança enquanto aprendiz lastreia o processo de mudança cognitiva para os contextualistas. Rogoff (1990) salienta que esta posição permite à criança iniciante não apenas acessar os aspectos explícitos da habilidade, mas também o acesso aos processos internos mais ocultos do pensamento. Os adultos nesse processo atuariam como incentivadores cognitivos na medida em que orientam e estimulam as crianças a desenvolverem todo seu potencial.

O paradigma vygotskyano também se configura como bastante contributivo, influenciando de maneira mais ou menos intensiva, os construtos teóricos elaborados em outras áreas, como a da neurociência cognitiva.

\section{A abordagem biológico-maturacional: neurociência cognitiva}

A abordagem biológico-maturacional sustentada pela neurociência cognitiva, apesar de apresentar algumas nuanças, enfatiza basicamente que o processo da mudança cognitiva ocorre devido à dotação genética e à maturação cerebral. Considera-se, por exemplo, que a maturação do lobo frontal influencia na noção de permanência de objeto (Diamond, 1991; citado por Flavell et al., 1999) e que a mente constitui-se por módulos mentais inatos (Fodor, 1983; citado por Flavell et al., 1999). Uma abordagem à consciência que se configura inovadora dentro desta área merece uma referência nesse momento: a neurociência cognitiva.

Damásio (2000) traz mais uma importante contribuição para os estudos da mente com o resgate da abordagem à consciência, já priorizada nos estudos de Luria e Vygotsky. Ele afirma que a mente consciente é constituída em parte, por um sentido do self. A sua concepção de mente refere-se a um processo que abrange tanto operações conscientes quanto inconscientes. De acordo com sua concepção, na perspectiva da neurobiologia, o problema da consciência consiste na combinação de dois problemas inter-relacionados. O primeiro diz respeito a entender como o cérebro humano engendra os padrões mentais denominados de imagens de um objeto e, o segundo, remete a como, paralelamente ao engendramento desses padrões mentais, o cérebro também engendra um sentido do self no ato de conhecer. Este segundo problema induziria à descoberta dos alicerces biológicos da capacidade humana em construir tanto padrões mentais de objetos quanto padrões mentais que transmitem o sentido de um self no ato de conhecer.

A neurociência cognitiva tem contribuído no sentido de associar, de maneira mais concreta, determinados comportamentos a marcadores específicos de estrutura ou atividade cerebral. As descobertas nesse campo têm contribuído para a identificação da arquitetura neural que sustenta a consciência, revelando a existência de uma relação entre alguns aspectos dos processos da consciência e as operações de regiões e sistemas cerebrais específicos. Ainda, têm comprovado que os estados de vigília e a atenção básica são distintos da consciência e, também, que consciência e emoção são processos indissociáveis, visto que o comprometimento de uma afeta a outra, e vice-versa. Por fim, duas descobertas foram de especial importância, denotando que a consciência humana não é um monólito, podendo ser separada em tipo simples e complexo e que as funções cognitivas como linguagem, memória, razão, atenção e memória operacional, são necessárias, apenas, aos níveis superiores da consciência ampliada.

A necessidade da consciência reside no fato de que ações eficazes requerem imagens eficazes, uma vez que estas permitem não apenas escolher a ação mais adequada e otimizar sua execução, mas, principalmente, porque permitem inventar novas ações apropriadas a situações inéditas e fazer planos para ações futuras (grifos nossos). Desta forma, o surgimento da consciência prenuncia a antevisão do indivíduo, ou seja, seu potencial para realizar inferências e interpretações. Origina-se como um sentimento que acompanha a produção de qualquer imagem (visual, tátil, etc.) dentro do organismo e torna-se conhecimento.

Em linhas gerais, Damásio (2000) salienta que a consciência tem início quando o cérebro adquire o simples poder de contar uma história sem palavras, uma história de que existe vida no organismo e que este vivencia incessantes mutações, dentro dos limites do corpo, a partir de suas relações com objetos e eventos ou por pensamentos e ajustes internos do processo da vida. Segundo ele, pode existir mente sem consciência, porque consciência e mente são instâncias distintas. A consciência seria uma parte da mente relacionada ao sentido manifesto do self e do conhecimento. Ele advoga uma possível relação de privilégio entre consciência e sentimento, uma vez que o sentimento pode estar situado no limiar entre o ser e o conhecer. Contudo, os processos da emoção (conjunto de reações, em geral, de caráter público e não exclusivamente humano) e do sentimento (experiência mental de uma emoção, de caráter privado), independem da consciência.

Através das ligações estabelecidas com as idéias, princípios e valores, as emoções tornam-se especialmente huma- 
nas. O sentimento gerado por estas emoções, intermediandoa do público ao privado, propicia seu impacto sobre a mente. Contudo, a consciência apresenta-se necessária ao impacto integral e duradouro do sentimento, já que seu conhecimento requer a integração com um sentido de self. Ao falar das emoções, Damásio (2000) adota a distinção entre primárias ou universais (tais como alegria, tristeza, medo, raiva, surpresa), secundárias ou sociais (ciúme, culpa, orgulho) e emoções de fundo (bem ou mal-estar, calma, tensão). Salienta que as emoções são conjuntos complexos de reações químicas e neurais que formam um determinado padrão e que estão ligadas ao corpo, sendo seu papel regulador o de preservar a vida do organismo. Elas são processos determinados biologicamente, dependendo de mecanismos cerebrais inatos e automatizados. Contudo, o desenvolvimento e a cultura influenciam marcantemente o seu produto final, seja adequando o indutor à determinada emoção, seja modelando alguns aspectos de sua expressão ou, ainda, moldando a cognição e o comportamento decorrentes de sua mobilização.

Para este teórico, haveria uma consciência central, que se caracteriza por ser uma estrutura simples, estável, encontrada também em animais não humanos, responsável pelo fornecimento de um sentido do self ao organismo no momento imediato (aqui e agora); e uma consciência ampliada, que corresponde a uma estrutura mais complexa, que se constitui num processo histórico-evolutivo, que varia em níveis e graus, fornecendo um sentido do self mais completo ao organismo, conferindo-lhe a conquista de uma identidade individual. Essa última, em seus níveis mais elevados, depende da memória convencional e da operacional, só sendo encontrada em seres humanos e intensificada pela linguagem. Assim, para ele, há uma coordenação desses dois tipos de consciência, uma sobreposição que unifica essas duas instâncias no funcionamento da consciência, observando-se que a consciência central constitui-se num alicerce da consciência ampliada. Esses dois tipos de consciência remetem também a distintas formas de self, que se mantêm inter-relacionadas.

De acordo com Damásio (2000), anterior ao sentido do self, há um precedente biológico pré-consciente, denominado de proto-self, que se define enquanto "um conjunto coerente de padrões neurais que mapeiam, a cada momento, o estado da estrutura física do organismo nas suas numerosas dimensões” (p. 201). A estrutura do proto-self não é constituída pela linguagem, não tem capacidade de percepção e não tem conhecimento. O proto-self é um conjunto de padrões neurais de primeira ordem que ocorre do tronco cerebral ao córtex cerebral, emergindo "dinâmica e continuamente de vários sinais em interação que abrangem diversas ordens do sistema nervoso” (p. 201). Posterior ao estabelecimento do proto-self, encontra-se o desenvolvimento de um self central, que tem caráter transitório e recria-se a cada interação do cérebro com os objetos; e um self autobiográfico, que mantém um caráter de dependência com lembranças sistematizadas de situações nas quais houve uma participação da consciência central no processo de conhecimento dos aspectos mais invariáveis da vida do organismo.
Em uma tentativa de compreender o processo do surgimento da consciência central, poder-se-ia dizer, de modo bastante insípido, que seu estabelecimento ocorre por meio da geração de um relato imagético, não-verbal, proveniente dos mecanismos cerebrais de representação, na medida em que o organismo sofre alteração em seu estado, decorrente do ato de processar um determinado objeto, suscitando um realce de sua imagem e, conseqüentemente, destacando sua existência espaço-temporal.

A conquista da consciência ampliada, na concepção de Damásio (2000), possibilita ao ser humano

atingir o ápice de suas capacidades mentais, tais como: criar artefatos úteis, levar em consideração a mente de outra pessoa, entender as mentes de uma coletividade, (...) valorizar a vida (...), levar em conta os interesses de outra pessoa e da coletividade, (...) perceber uma discordância de sentimentos e depois uma discordância de idéias abstratas, o que é a origem do senso da verdade. (p. 294)

Nesse processo, ele dá especial destaque à primeira, pela possibilidade de superação dos próprios limites de sobrevivência e, à segunda, pelo fato de que é a "percepção crítica de discordâncias, que leva à busca da verdade e ao desejo de criar normas e ideais para o comportamento e para a análise dos fatos” (p. 295), possibilitando, dessa maneira, alcançar a consciência moral, considerada enquanto uma função verdadeiramente humana.

\section{Considerações Finais}

Almejar uma conceituação única e, ao mesmo tempo, explicativa de todas as nuanças da cognição, apresenta-se como uma perspectiva de improvável êxito, visto que sua definição requer, já a priori, uma diferenciação de sujeito ser humano ou não-humano -, além da adoção de uma determinada teoria que lhe sirva de lastro. Em outras palavras, a discriminação dos aspectos filogenético e ontogenético que caracterizam a cognição, requer o suporte de um paradigma específico que, necessariamente, conduz a relevância de certos atributos e ao descarte de outros.

Considera-se, pois, em consonância com Flavell et al. (1999), que os paradigmas anteriormente apresentados tendem a ser mais complementares que excludentes, uma vez que priorizam aspectos distintos do desenvolvimento cognitivo, refletindo a riqueza e complexidade da mente humana.

\section{Referências}

Álvarez, A., \& Del Rio, P. (1996). Educação e desenvolvimento: a teoria de Vygotsky e a zona de desenvolvimento próximo. In C. Coll, J. Palácios, \& A. Marchesi (Orgs.), Desenvolvimento psicológico e educação: psicologia da educação (pp. 79-104). Porto Alegre: Artes Médicas.

Astington, J. W. (Org.). (2000). Minds in the making. Essays in honor of David R. Olson. Oxford: Blackwell.

Bruner, J. (1997). Atos de significação. Porto Alegre: Artes Médicas.

Carvalho, L. A. V. (1998). Teoria da Mente: a alma humana em busca de si mesma. In S. Fuks (Org.), Descartes 400 anos: um legado científico e filosófico (pp. 201-215). Rio de Janeiro: Relume Dumará. 
Coll, C., \& Gillièron, C. (1987). Jean Piaget: o desenvolvimento da inteligência e a construção do pensamento racional. In L. B. Leite \& A. A. Medeiros (Org.), Piaget e a Escola de Genebra (pp. 13-50). São Paulo: Cortez.

Damásio, A. (2000). O mistério da consciência: do corpo e das emoções ao conhecimento de si. São Paulo: Companhia das Letras.

Flavell, J. H. (1988). A psicologia do desenvolvimento de Jean Piaget. São Paulo: Pioneira.

Flavell, J. H., Miller, P. H., \& Miller, S. A. (1999). Desenvolvimento cognitivo. Porto Alegre: Artes Médicas.

Karmilloff-Smith, A. (1986). From meta-processes to conscious access: evidence from children's metalinguistic and repair data. Cognition, 23, 95-147.

Leóntiev, A. N. (1999). Artigo de introdução sobre o trabalho criativo de L. S. Vigotski. In L. S. Vigotski. Teoria e método em Psicologia (pp. 425-470). São Paulo: Martins Fontes.

Lyra, M. C. D. P., \& Seidl de Moura, M. L. (2000). Desenvolvimento na interação social e no contexto histórico-cultural: adequação entre perspectiva teórica e metodológica. Psicologia Reflexão e Crítica, 13(2), 217-222.

Oliveira, M. K. (1992). Vygotsky e o processo de formação de conceitos. In Y. de La Taille, M. K. Oliveira, \& H. Dantas (Orgs.), Piaget, Vygotsky, Wallon: teorias psicogenéticas em discussão (pp. 23-34). São Paulo: Summus.

Olson, D. R. (1988). On the origins of beliefs and other intentional states in children. In J. W. Astington, P. L. Harris, \& D. R. Olson (Orgs.), Developing theories of mind (pp. 414-426). Cambridge: Cambridge University Press.
Piaget, J. (1973). A linguagem e as operações intelectuais. In J. Ajuriaguerra, F. Bresson, P. Fraisse, B. Inhelder, \& P. Oléron (Orgs.), Problemas de psicolingüística (pp. 63-74). São Paulo: Mestre Jou.

Piaget, J. (1978). A formação do símbolo na criança. Rio de Janeiro: Zahar.

Rego, T. C. (1995). Vygotsky - uma perspectiva histórico-cultural da educação. Petrópolis: Vozes.

Reig, D., \& Gradoli, L. (1998). A construção do conhecimento na educação. Porto Alegre: Artes Médicas.

Rogoff, B. (1990). Apprenticeship in thinking. Nova York: Oxford University Press.

Searle, J. (1984). Minds, brains and science. Cambridge, Massachusetts: Harvard University Press.

Siegler, R. S. (1991). Children's thinking ( $2^{\underline{a}}$ ed.). Englewood Cliffs, New Jersey: Prentice-Hall.

van der Veer, R., \& Valsiner, J. (1996). Vygotsky: uma síntese. São Paulo: Unimarco.

Vygotsky, L. S. (1993). Pensamento e linguagem. São Paulo: Martins Fontes. Vygotsky, L. S. (1998a). Problemas de Método. In A formação social da mente (pp. 67-85). São Paulo: Martins Fontes.

Vygotsky, L. S. (1998b). As emoções e seu desenvolvimento na infância. In O desenvolvimento psicológico na infância (pp. 79-106). São Paulo: Martins Fontes.

Wertsch, J. V. (1985). Vygotsky and the social formation of mind. Cambridge, Massachusetts: Harvard University Press.

Suely de Melo Santana, mestra em Psicologia Cognitiva pela Universidade Federal de Pernambuco e doutoranda em Psicologia pela Faculdade de Psicologia e de Ciências da Educação da Universidade do Porto (Portugal), é professora assistente na Universidade Católica de Pernambuco. Endereço para correspondência: Rua Príncipe, 526; Boa Vista; Recife, PE; CEP: 50050-900. Tel: (81) 3216-4172. E-mail: ssantana@unicap.br Antonio Roazzi, doutor pela Universidade de Oxford (Reino Unido), é professor adjunto no Programa de Pósgraduação em Psicologia da Universidade Federal de Pernambuco.

Maria das Graças B. B. Dias, doutora pela Universidade de Oxford (Reino Unido), é professora adjunta no Programa de Pós-graduação em Psicologia da Universidade Federal de Pernambuco. 